\title{
OS DESAFIOS DA EDUCAÇÃO SUPERIOR NA IBERO-AMÉRICA: INOVAÇÃO, INCLUSÃO E QUALIDADE
}

\author{
Dilvo RistofF*
}

Recebido: 10 set. 2013

Aprovado: 20 set. 2013

* Centro de Comunicação e Expressão, Departamento de Língua e Literatura Estrangeiras da Universidade Federal de Santa Catarina. Florianópolis, SC, Brasil.

Contato com o autor: ristoff.dilvo@gmail.com

Resumo: À luz de ações postas em prática no Brasil e em outros países da Ibero-América, nos últimos anos, o texto discute o chamamento à ação feito pela Conferência Mundial da Educação Superior de 2009, organizadas pela UNESCO e aponta para avanços e entraves (1) nas políticas públicas de garantia de qualidade e seus respectivos processos de desenvolvimento de sistemas nacionais de avaliação e regulação da educação superior; (2) nas políticas de inclusão, pertinência social e pleno aproveitamento das potencialidades humanas das comunidades; e (3) nas políticas de inovação e uso intensivo de novas tecnologias de informação e comunicação. O texto argumenta que temas historicamente considerados tabu começam a se tornar sustentáculos importantes das políticas públicas da região.

Palavras-chave: Conferência Mundial da Educação Superior; Qualidade, Avaliação, Inclusão; Inovação.

\section{THE CHALLENGES OF HIGHER EDUCATION IN IBERO-AMERICA: INNOVATION, INCLUSION, AND QUALITY.}

Abstract: In light of actions implemented in Brazil and other countries of Ibero-America in recent years, the text discusses the call to action made by the World Conference on Higher Education, 2009, organized by UNESCO and points to advances and obstacles (1 ) in quality assurance public policies and their respective processes of development of national systems of evaluation and regulation of higher education, (2) in the inclusion policies, social relevance and use of the full potential of communities, and (3) in the policies of innovation and intensive use of new information and communication technologies. The text argues that issues historically considered taboo start to become important mainstays of public policies in the region.

Keywords: World Conference on Higher Education, Quality, Evaluation, Inclusion, Innovation

Nações soberanas, democráticas, inclusivas, emancipadoras e avançadas nas artes, nas ciências e nas tecnologias: é com essa imagem de futuro que a comunidade internacional trabalha. Pelo menos aqueles países signatários da Conferência Regional de Educação Superior (CRES), realizada em Cartagena de Índias, na Colômbia, em junho de 2008, e da Conferência Mundial de Educação Superior (CMES), realizada em Paris, em julho de 2009, ambas promovidas pela Unesco. 
É importante observar que os dois documentos finais destas conferências deixam claro que se trata de uma missão que supera o presente e insere-se em um futuro imaginado, um futuro - para muitas nações do mundo, e para a América Latina e Caribe em especial - distinto do presente. Por isso mesmo, a conferência estabeleceu muito nitidamente, e expressamente, repetindo a declaração da Conferência Mundial de dez anos antes, que a educação superior é um "bem público" e não uma mercadoria. Um bem que deve estar no âmbito público, ser do público, ser orientado para o público e que deve desempenhar as suas funções em prol do público, sendo responsabilidade de todas as partes interessadas, de todos os investidores e, em especial, dos governos. ${ }^{1}$

Estabeleceu mais: que a educação superior é também "um imperativo estratégico", ou seja, as instituições que dela se ocupam precisam se impor como lideranças nesta jornada rumo a uma nova sociedade - uma sociedade na qual as nações possam comandar os seus próprios destinos, colocar-se a serviço de todos e não apenas de grupos privilegiados; assegurar a todos os que concluíram o ensino médio as oportunidades para continuarem os seus estudos; ter sistemas educacionais de qualidade que permitam aos cidadãos colocarem as suas energias criativas a serviço do desenvolvimento e da melhoria da qualidade de vida de suas sociedades. Esta liderança na caminhada para o futuro demanda que as instituições de educação superior assumam, decididamente, a liderança em matéria de geração de conhecimentos para abordar os grandes desafios mundiais que se impõem ${ }^{2}$. Entre os desafios mundiais destacados pela CMES estão:

a) a segurança alimentar,

b) as mudanças climáticas,

c) a gestão da água,

d) o diálogo intercultural,

e) as energias renováveis,

f) a saúde pública,

g) a construção da paz,

h) a defesa dos direitos humanos,

i) o cultivo dos valores da democracia e

j) a promoção da equidade e da justiça social.

1 A CMES declara textualmente que "A Educação Superior como um bem público é responsabilidade de todos os investidores, especialmente dos governantes".

2 Com relação à importância da educação superior, a CRES de 2008 também se manifesta declarando: "Em um mundo onde o conhecimento, a ciência e a tecnologia desempenham um papel de primeira grandeza, o desenvolvimento e o fortalecimento da Educação Superior constituem um elemento imprescindível para o avanço social, a geração de riqueza, o fortalecimento das identidades culturais, a coesão social, a luta contra a pobreza e a fome, a prevenção da mudança climática e a crise energética, assim como para a promoção de uma cultura de paz". 
O papel das universidades, como instituições de ensino, pesquisa e extensão, com mestrados e doutorados e espaços privilegiados para estudos aprofundados em todas as áreas do conhecimento, torna-se, portanto, fundamental e estratégico neste contexto de busca de sustentabilidade para a vida na terra. A questão ganha importância quando se percebe que, não raro, outros setores da sociedade são menos conservadores e tão ou mais ágeis na produção de conhecimentos que as universidades. Mesmo assim, as universidades continuam a ser percebidas como a principal fonte de identificação de talentos para estudos avançados, para a pesquisa e a inovação.

Em momentos em que questões como as acima apontadas despontam como centrais para a preservação da vida no planeta, as universidades, mesmo com suas limitações, são chamadas a assumir papel de protagonistas nos debates que se farão necessários. A percepção dos elaboradores do documento é que, a menos que se abordem estas questões presentes e prementes com firmeza e seriedade, estaremos permitindo que se construam as "represas" das quais nos fala Alvin Tofler, em seu livro Choque de Futuro - "represas" que nos surpreenderão e que, talvez de forma potencialmente trágica, tornarão inviável a nossa imagem de futuro.

O Relatório final da Conferência Mundial da Educação Superior contém quatro partes, que tratam, a saber, de:

I - Responsabilidade Social;

II - Acesso, Equidade e Qualidade;

III - Internacionalização, Regionalização e Mundialização; e

IV - Aprendizagem, Pesquisa e Inovação.

Após explorar essas quatro partes, o relatório conclui fazendo um convite à ação. O objetivo deste trabalho é discutir alguns aspectos desse convite em sua relação com a inclusão, a inovação e a qualidade da educação superior, tendo sempre em mente que, ao discutir a qualidade deste nível educacional, há que se ter, nos processos avaliativos, clareza sobre a missão que se pretende atribuir às Instituições de Educação Superior (IES), considerando os seus limites e possibilidades para as próximas décadas.

Com relação à primeira parte, a da Responsabilidade Social, o relatório reafirma, como já destacado, a declaração de 1988, de que a educação superior é um bem público ${ }^{3}$ e um imperativo estratégico, estando, portanto, associada

3 Com relação a esta questão, a CRES é também muito enfática ao declarar: (1) “A Educação Superior é um direito humano e um bem público social. Os Estados têm o dever fundamental de garantir este direito". 
à imagem de futuro que se pretende para o conjunto de países que assinam o documento. $\mathrm{O}$ texto estabelece ainda, já na sua Introdução, que a educação superior deve garantir acesso igual a todos, em função dos méritos. ${ }^{4}$

A primeira grande responsabilidade social da educação superior, portanto, está associada ao acesso igualitário a todos e não apenas a alguns poucos. A observação de que o acesso deve depender dos méritos dos indivíduos, no entanto, envia sinais ambíguos aos formuladores das políticas educacionais. Se, por um lado, afirma a necessidade de inclusão de todos os segmentos sociais, por outro lado deixa implícita a preocupação de que as ações afirmativas, que justamente privilegiam grupos sociais vítimas de exclusão histórica, possam colocar em risco a qualidade do ensino. Reverbera neste discurso a mesma mensagem que se ouve com freqüência, como uma espécie de cantochão, nos campi das grandes universidades do Brasil: "a inclusão virá em detrimento da qualidade!" Efetivamente, este temor tem sido talvez o maior dos inimigos da democratização do acesso. O texto da Unesco reproduz esse entendimento.

Da mesma forma, se posicionou o parlamento brasileiro que, em 2001, aprovou a lei que criou o Plano Nacional de Educação (PNE). No tocante à educação superior, o PNE evidencia que os parlamentares à época acalentavam preocupações contraditórias muito semelhantes às da Unesco: primeiro, a necessidade de oferecer a um maior número de jovens a oportunidade de continuarem os seus estudos após a conclusão do ensino médio e, segundo, o temor da massificação do ensino superior. Fica claro o temor de que, havendo massificação, a qualidade do ensino se deteriore. É importante lembrar que, à época, o Brasil tinha uma das menores taxas de escolarização da América Latina (em torno de $9 \%$ dos jovens de 18 a 24 anos de idade). Nem por isso poderia se afirmar que ostentava a melhor qualidade educacional do mundo, deixando evidente que pequena quantidade não é necessariamente sinônimo de alta qualidade. As estatísticas educacionais mostram que somente nas últimas duas décadas mudou, no Brasil, a compreensão sobre esta questão qualidade versus quantidade no ensino fundamental e que agora começa a mudar também no ensino médio e superior, tornando possível uma expansão das matrículas mais compatível com o desejável para as nações.

A democratização agressiva do acesso à educação superior, nos números e termos preconizados pelo governo e pelos dois Planos Nacionais de Educação

4 A Introdução do texto final da CMES declara textualmente: "Conforme destacado na Declaração Universal dos Direitos Humanos, 'o ensino superior deve ser igualmente acessível para todos na base do mérito " (Artigo 26, Parágrafo 1)". 
(PNE), que nos levaria a consolidar até 2020 o que Martin Trow (2005) denominou sistema de educação superior de massas, coloca em cheque concepções elitistas e excludentes que sustentam hoje boa parte de nossas instituições. Como destacávamos no livro Construindo Outra Educação, "o sistema de elite é pequeno, excludente e catedrático, às vezes quase privado, mesmo no espaço público, e se imagina como um lugar onde alguns poucos jovens, altamente inteligentes e rigorosamente selecionados sentam-se ao lado de professores doutores atenciosos e sábios - um local de alta cultura e de tradições seculares, que remontam aos tempos medievais. O sistema inclusivo é, por natureza, muito diferente e, de certo modo, se contrapõe a isso. Ele é amplo, diversificado, democrático, de massas, preocupado em dar a todos uma oportunidade. Em muitos casos, o sistema inclusivo, pelas modalidades contemporâneas de e-learning e de educação aberta e a distância, das quais se utiliza, deixou de ser até mesmo um lugar". 5

A fase de transição que vive a educação superior do Brasil, em função dos números projetados para as metas do próximo PNE (aproximadamente 14 milhões de alunos até 2022), deverá nos levar a um agravamento da crise dos valores acadêmicos hegemônicos e a uma certamente tensa convivência de modelos diversificados.

Se seremos capazes de apreciar o novo pelo que ele realmente é e significa para a nossa imagem de futuro, só o tempo dirá.

A segunda responsabilidade nos diz dos múltiplos interesses associados à educação superior (pais, alunos, empregadores, empresários, etc.), enfatizando que, embora a educação possa ser responsabilidade de muitos, a responsabilidade principal é dos governos, ou seja, dos Estados. Se observarmos esta afirmação à luz dos dados do Censo da Educação Superior do Brasil, vemos que há um longo caminho a trilhar até podermos dizer que a educação superior brasileira é essencialmente pública. Hoje, $89 \%$ das instituições de educação superior e $75 \%$ das matrículas pertencem ao setor privado. A Conferência Regional

5 "Há, paradoxalmente, nos ganhos da inclusão um forte sentimento de perda, tanto entre os habituados a conviver com o sistema de elite como entre os excluídos que obstinadamente o procuram. O sentimento de perda, estranhamente, parece atingir a todos. Observa-se que à medida que o sistema inclusivo se instala, instituições as mais diversas, mesmo as sem qualquer tradição, buscam recuperar os símbolos de prestígio associados à universidade de elite tradicional: os rituais, a beca, o capelo, os medalhões, a sobrepeliz, o espaço restrito, aconchegante, reservado, o tratamento personalizado, centrado no indivíduo. Ironicamente estes símbolos tradicionais ganham mais e não menos força, buscando recuperar o status, a vantagem, o destaque, perdidos com a popularização do diploma. A mensagem parece ser a de que, embora o diploma não tenha mais o charme de antigamente, identificando o seu portador com as elites privilegiadas, ele ainda assim emblematiza as novas portas que se abrem. E isso, embora possa parecer pouco aos bem aquinhoados, é a própria oportunidade de mobilidade social de muitos. Merece, pois, ser celebrado!" (RISTOFF, 2011, p. 58) 
reconhece que este é um problema de toda a Região e, por isso mesmo, foi muito enfática ao alertar que "A Educação Superior como bem público social enfrenta correntes que promovem sua mercantilização e privatização, assim como a redução do apoio e financiamento do Estado. É fundamental reverter esta tendência, de tal forma que os governos da América Latina e do Caribe garantam o financiamento adequado das instituições de Educação Superior pública e que estas respondam com uma gestão transparente. A Educação não pode, de modo algum, reger-se por regulamentos e instituições com fins comerciais, nem pela lógica do mercado". Ainda assim, as duas Conferências deixam claro que, considerando a imensa necessidade de expandir a cobertura da educação superior nos países da América Latina e do Caribe, "tanto o setor público quanto o privado estão obrigados a outorgar uma Educação Superior com qualidade e pertinência". Considerando-se, no entanto, os altos índices de privatização ocorrida nas últimas décadas, as declarações da CMES e da CRES são para o Brasil nada mais do que um alerta. Não obstante todos os esforços feitos nos últimos dez anos no sentido da expansão das universidades públicas, o Brasil continua na contramão, ridicularizando o que os participantes das Conferências imaginam que a educação superior deveria ser. E a América Latina, com raras exceções, aos poucos caminha no mesmo sentido. Estudos têm demonstrado que já em 1998, por ocasião da Conferência Mundial da Educação Superior, os percentuais de privatização em muitos países da América Latina já se encontravam elevados, com Brasil, Chile e Colômbia, por exemplo, com percentuais de matrículas privadas próximas a 60\%. Em 2007, oito países da América Latina já tinham percentuais próximos ou superiores a $50 \%$ das matrículas no setor privado, com Chile, Brasil, El Salvador e Colômbia com os mais altos índices e com Uruguai, Bolívia, Panamá e Argentina resistindo bravamente às investidas do setor privado. O que se observa mais recentemente é que há um crescimento relativo constante das matrículas do setor privado na quase totalidade dos sistemas nacionais latino-americanos.

O compromisso, por fim, com a construção da paz, com a defesa dos direitos humanos e com a democracia é mais importante hoje do que em qualquer época. As guerras localizadas que proliferam e que põem em cheque as noções civilizadas de tolerância às diferenças, combinadas à crescente capacidade humana de destruir, exigem cuidados redobrados para que não se instalem as tiranias e para que possa proliferar a inteligência democrática, com a participação de todos os segmentos de todas as sociedades do planeta.

Com relação à segunda parte do relatório da CMES, que está diretamente vinculada à questão da avaliação da qualidade, acesso, equidade e qualidade, 
o documento estabelece as seguintes linhas de ação a serem seguidas pelos governos nacionais:

- Ampliação do acesso, com qualidade, equidade e pertinência;

- Apoio econômico e educativo para os estudantes de comunidades pobres e marginalizadas;

- Diversificação dos sistemas de educação superior;

- Participação de entidades privadas de educação superior com objetivos de interesse público;

- Formação de docentes, para dotar a eles e a seus alunos das competências de que necessitam no século XXI;

- Uso da aprendizagem aberta e a distância e das tecnologias de informação e comunicação (TIC);

- Promoção de pesquisas para melhorar as estratégias didáticas;

- Criação de sistemas para garantir a qualidade;

- Critérios de qualidade que reflitam os objetivos globais da educação superior;

- Reconhecimento da importância de atrair e reter um corpo docente e de pesquisa qualificado, talentoso e comprometido com o seu trabalho;

- Ter políticas de investimentos que prestem apoio a uma ampla gama de atividades de educação e pesquisa.

Este conjunto de linhas de ação foi seguido de um convite à ação, cujas três grandes preocupações temáticas (inovação, inclusão e qualidade) merecem ser discutidas. Convém lembrar, no entanto, que o convite à ação é um conjunto de recomendações ou orientações, entendidas como non-binding, ou seja, sem aplicação compulsória pelos países signatários.

A primeira destas recomendações reza:

"Manter e se possivel aumentar a alocação de recursos para a educação superior, para apoiar a qualidade, a equidade e a diversificação".

Percebe-se com relação a esta ação, a nítida percepção da Unesco de que mudanças significativas na educação estão diretamente associadas à quantidade de recursos a serem investidos. O entendimento parece inequívoco: ou o recurso acompanha o discurso, ou as chances de as políticas públicas para o setor fracassarem são grandes. Percebe-se outra vez a preocupação em assegurar a qualidade à medida que oportunidades são oferecidas para as classes historicamente excluídas. 
Nota-se ainda a reafirmação de que a educação não deve se pautar por um modelo único, mas por um modelo diversificado de instituições de educação superior - em perfeita sintonia com as orientações do Banco Mundial e em confronto direto com uma das bandeiras históricas do movimento docente brasileiro.

Como está o Brasil e como estão outros países da América Latina com relação a esse chamamento?

Em termos de alocação de recursos, há que se destacar que os investimentos para as IFES têm crescido ano a ano desde 2003, tanto em termos absolutos (de 15 bilhões para 30 bilhões) quanto em relação ao PIB (de $0,52 \%$ para $0,78 \%$ ). A proposta para 2020 é elevar o investimento em educação para $10 \%$ do PIB (Em 2012 estava em torno de 5\%) e o investimento nas IFES, de 0,78\% para no mínimo $1,2 \%$ do PIB.

O gráfico abaixo explicita o investimento em educação feito pelos países da Ibero-América.

\section{Gráfico 1 - Percentual do PIB aplicado em}

Educação em países da Ibero América

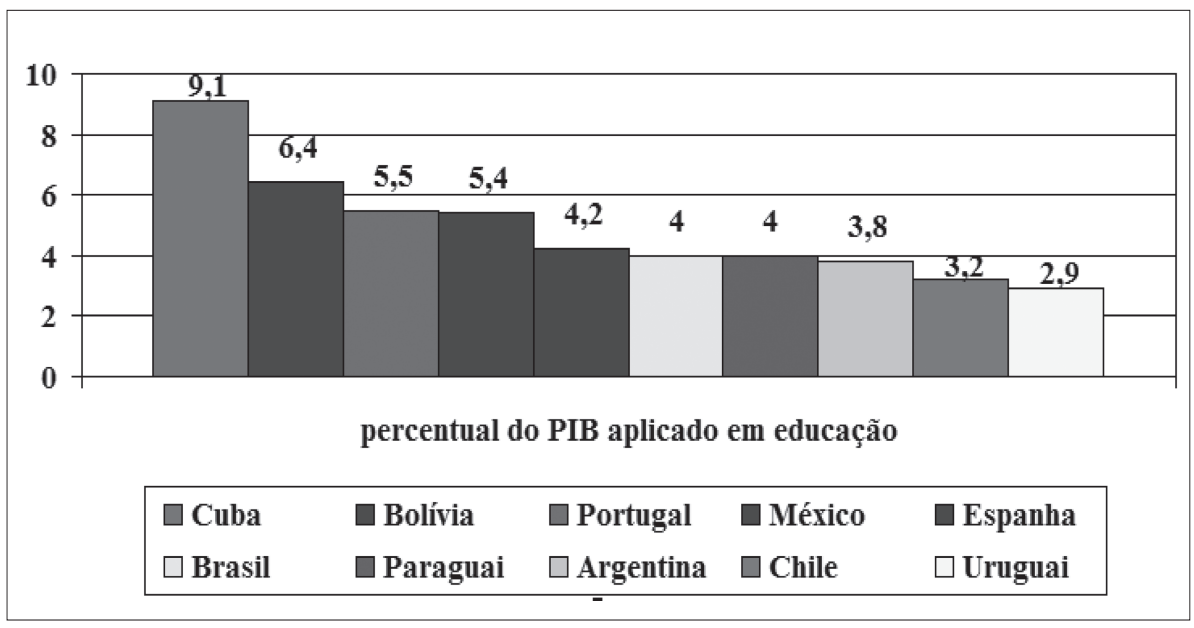

Fonte: (UNESCO, 2010) e (EUA. CIA, 2010) e cálculos de Nelson Amaral e deste estudo.

Percebe-se, portanto, que Cuba e Bolívia lideram o ranking, aplicando um percentual maior do PIB do que todos os demais países, inclusive mais do que Portugal e Espanha. Aplicam percentuais maiores do que Rússia, Canadá, Japão, Estados Unidos e outros países, como se pode ver abaixo: 
Tabela 1 - Valores aplicados em educação como percentual do PIB - países selecionados

\begin{tabular}{llll}
\hline País & $\begin{array}{l}\text { \% do PIB } \\
\text { aplicado } \\
\text { em educação }\end{array}$ & País & $\begin{array}{l}\text { \% do PIB } \\
\text { aplicado em } \\
\text { educação }\end{array}$ \\
\hline Yemen & 9,6 & Rússia & 3,8 \\
Índia & 3,2 & Portugal & 5,5 \\
Paraguai & 4 & Coréia do Sul & 4,6 \\
Bolívia & 6,4 & França & 5,7 \\
Indonésia & 3,2 & Dinamarca & 8,3 \\
China & 1,9 & Canadá & 5,2 \\
Brasil & 4,0 & Espanha & 4,2 \\
Botswana & 8,7 & Austrália & 4,5 \\
África do Sul & 5,4 & Alemanha & 4,6 \\
Cuba & 9,1 & Japão & 4,9 \\
México & 5,4 & Estados Unidos & 5,3 \\
Argentina & 3,8 & Áustria & 5,4 \\
Chile & 3,2 & Noruega & 7,2 \\
Uruguai & 2,9 & & \\
\hline
\end{tabular}

Fonte: (UNESCO, 2010) e (EUA: CIA, 2010) e cálculos de Nelson Amaral e deste estudo.

Portanto, se o percentual do PIB fosse suficiente para dizer do desafio posto pela educação inclusiva, Yemen, Bolívia e Botswana estariam em melhor situação que Estados Unidos, Japão e os países da Europa. No entanto, como bem alerta Nelson Amaral (2013), para se ter um retrato mais fiel do tamanho do desafio de cada nação, há que se considerar também o valor do PIB e, principalmente, o percentual da população em idade escolar e que precisa ser atendida com estes recursos.

Para demonstrar esta tese, Nelson Amaral (2013) compara o percentual do PIB da Bolívia com o do Canadá, conforme a seguir: 
Tabela 2 - Recursos financeiros aplicados no setor educacional, por pessoa em idade educacional (Bolívia e Canadá)

\begin{tabular}{llllll}
\hline País & $\begin{array}{l}\text { \% PIB aplicado } \\
\text { em educação }\end{array}$ & $\begin{array}{l}\text { PIB/PPP em } \\
\text { US\$ bilhões } \\
\text { (de 2009) }\end{array}$ & $\begin{array}{l}\text { Total de recursos } \\
\text { em educação } \\
\text { (US\$ bilhões) }\end{array}$ & $\begin{array}{l}\text { População } \\
\text { em idade } \\
\text { educacional }\end{array}$ & $\begin{array}{l}\text { Valor aplicado por } \\
\text { pessoa em idade } \\
\text { educacional (US\$) }\end{array}$ \\
\hline Bolívia & 6,4 & 45 & 2,9 & 4.142 .335 & 695,00 \\
Canadá & 5,2 & 1.278 & 66,5 & 8.656 .329 & $7.731,00$ \\
\hline
\end{tabular}

Fonte: (UNESCO, 2010) e (EUA: CIA, 2010) e cálculos de Nelson Amaral e deste estudo.

Observa-se que a Bolívia aplica 6,4\% do PIB e o Canadá 5,2\%. O PIB da Bolívia, no entanto, é de US\$ 45 bilhões e o do Canadá, US\$ de 1.2 trilhões. Isto significa dizer que o Canadá aplica 66 bi contra apenas 3 bi da Bolívia, ou seja, o Canadá aplica em números absolutos quase vinte e três vezes mais do que a Bolívia. Com vinte e três vezes mais de recursos, o Canadá atende apenas o dobro de pessoas que a Bolívia, tornando a sua aplicação per capita onze vezes maior.

Se compararmos o percentual do PIB dos países ibero-americanos com a aplicação per-capita à população em idade escolar, vemos que há uma significativa mudança nos posicionamentos dos países da região:

Tabela 3 - Valores aplicados em educação como percentual do PIB e US\$ por pessoa em idade educacional - em dez países ibero-americanos

\begin{tabular}{lrrrr}
\hline País & $\begin{array}{r}\text { \% do PIB } \\
\text { aplicado em } \\
\text { educação }\end{array}$ & Ranking & $\begin{array}{r}\text { US\$ por pessoa } \\
\text { em idade } \\
\text { educacional }\end{array}$ & Ranking \\
\hline Cuba & 9,1 & $1^{\circ}$ & 3.650 & $7^{\circ}$ \\
Bolívia & 6,4 & $2^{\circ}$ & 1.086 & $9^{\circ}$ \\
Portugal & 5,5 & $3^{\circ}$ & 10.166 & $2^{\circ}$ \\
México & 5,4 & $4^{\circ}$ & 3.738 & $6^{\circ}$ \\
Espanha & 4,2 & $5^{\circ}$ & 15.420 & $1^{\circ}$ \\
Brasil & 4,0 & $6^{\circ}$ & 2.398 & $8^{\circ}$ \\
Paraguai & 4,0 & $7^{\circ}$ & 1.020 & $10^{\circ}$ \\
Argentina & 3,8 & $8^{\circ}$ & 4.152 & $5^{\circ}$ \\
Chile & 3,2 & $9^{\circ}$ & 4.425 & $4^{\circ}$ \\
Uruguai & 2,9 & $10^{\circ}$ & 4.647 & $3^{\circ}$ \\
\hline
\end{tabular}

Fonte: (UNESCO, 2010) e (EUA:CIA, 2010) e cálculos de Nelson Amaral e deste estudo. 
Cuba, por exemplo, passa de primeiro lugar para sétimo, a Bolívia passa de segundo para nono e o Uruguai de décimo para terceiro. Os primeiros lugares no investimento per capita ficam com Espanha e Portugal, embora tenham um percentual do PIB menor do que o de alguns países da América Latina.

Entende-se melhor, portanto, o tamanho do desafio dos países latino-americanos se for incluído nos cálculos o percentual da população jovem e em idade escolar, pois desta depende em grande parte o valor efetivamente aplicado por aluno.

\section{Gráfico 2 - Percentual da População com Idade \\ Escolar em países da Ibero-América}

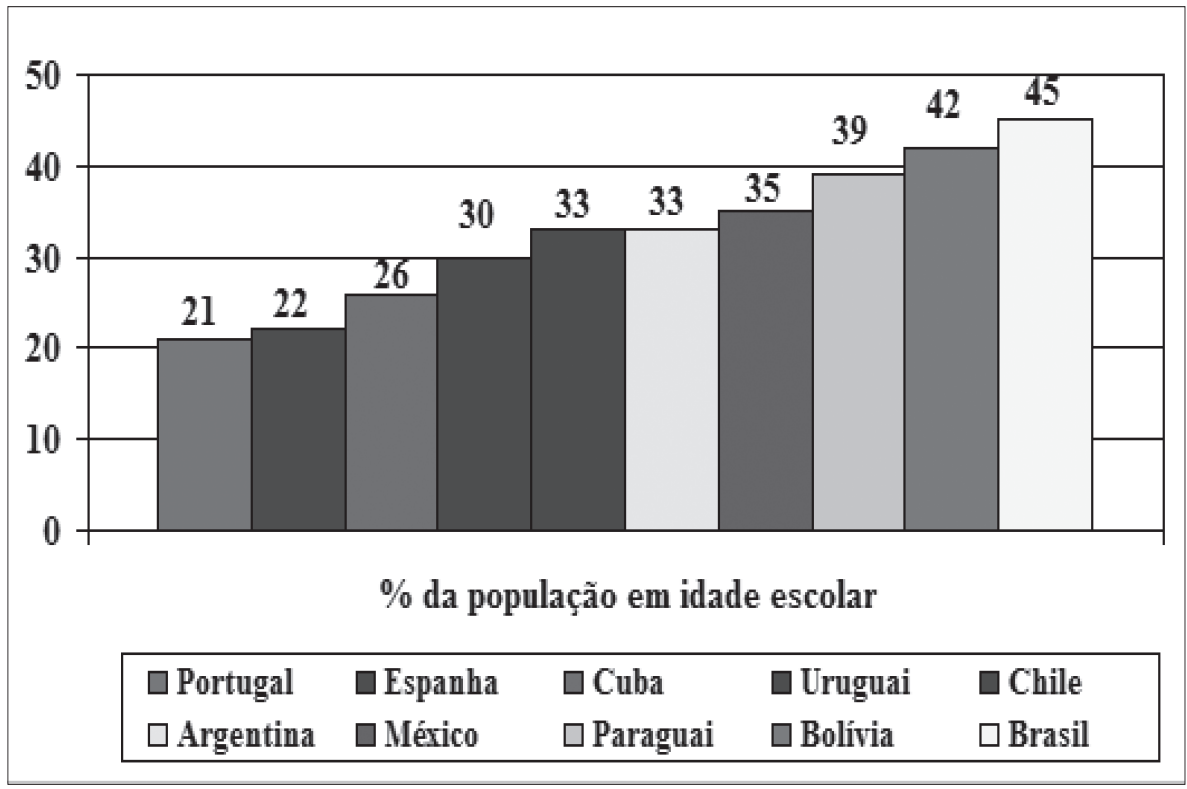

Fonte: (UNESCO, 2010) e (EUA: CIA, 2010) e cálculos de Nelson Amaral e deste estudo.

O gráfico acima nos mostra que o Brasil tem quase a metade de sua população em idade escolar e, percentualmente, mais que o dobro de pessoas nesta faixa etária do que têm Portugal e Espanha. Se a comparação for ampliada para incluir outros países do mundo, observa-se que o Brasil tem hoje um dos maiores desafios educacionais do planeta. Ver gráfico a seguir: 
Gráfico 3 - Percentual da população em idade escolar em alguns países

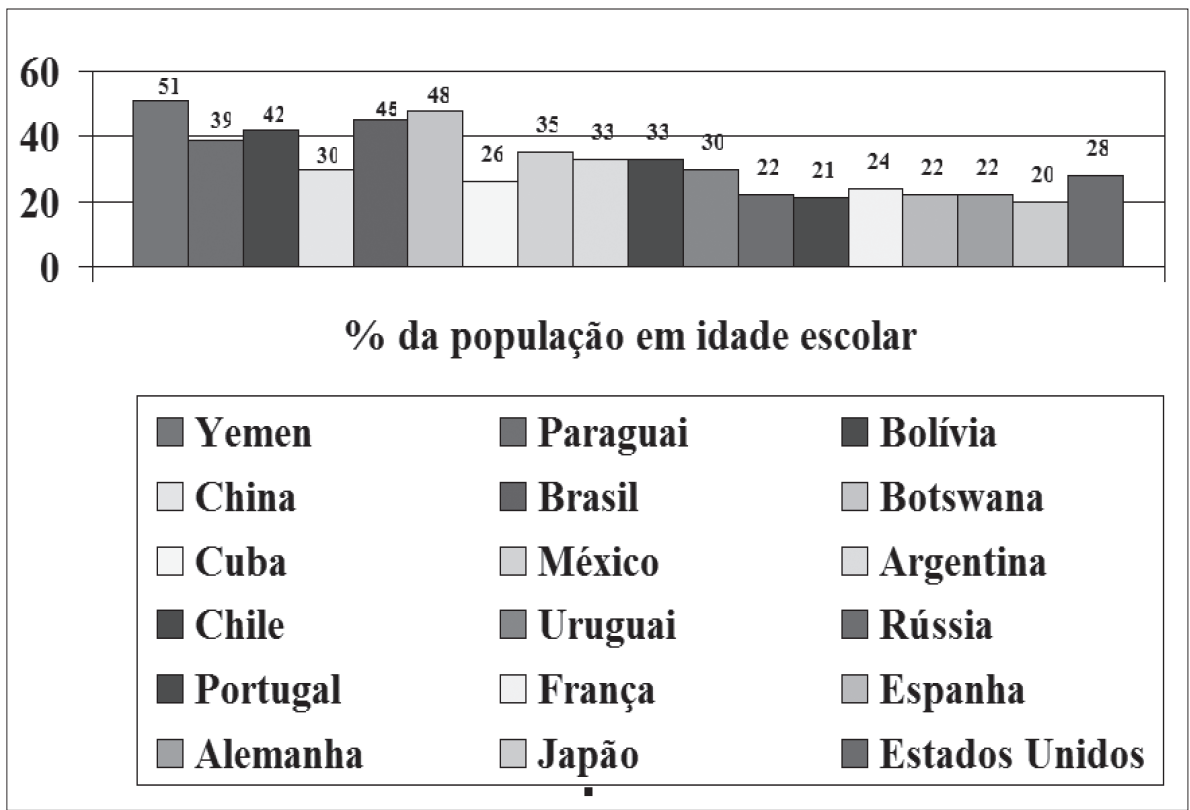

Fonte: (UNESCO, 2010) e (EUA: CIA, 2010) e cálculos de Nelson Amaral e deste estudo.

O gráfico acima mostra que Brasil só tem população em idade escolar menor do que Yemen (51\%) e Botswana (48\%), e que todos os países da América Latina, exceto Cuba (26\%) e Uruguai (30\%), têm população em idade escolar superior à média mundial (30\%), o que torna o desafio educacional da Região, para dizer pouco, gigantesco.

No caso do Brasil, cabe destacar ainda uma questão que aumenta o tamanho do seu desafio. Com apenas 15 de cada 100 jovens de 18 a 24 anos na educação superior (quando este percentual supera $40 \%$ na maioria dos países da Europa, Coreia, Japão, EUA, Canadá, etc.), o Brasil vem fazendo esforço significativo através de programas importantes de apoio estudantil, como Programa Universidade para Todos (ProUni), programa de democratização de acesso, via renúncia fiscal, para estudantes carentes em instituições privadas; Programa de Apoio a Planos de Reestruturação e Expansão das Universidades Federais (Reuni), interiorizando a educação superior pública, criando novos campi e novas universidades federais; Programa de Financiamento Estudantil para a Educação Superior Privada (FIES), Plano Nacional de Assistência Estudantil (PNAES) - programa de apoio à permanência de estudantes de baixa renda 
matriculados em cursos de graduação presencial das instituições federais de ensino superior (IFES), entre outros. Uma análise dos dados do último censo da educação superior de 2011 do Inep (2013) nos mostra que mais da metade da população universitária brasileira hoje está acima da idade escolar convencionada (24 anos) e, mais preocupante, cerca de 600 mil estudantes têm mais de 40 anos de idade.

\section{Gráfico 4 - Matrículas na Graduação por Faixa Etária}

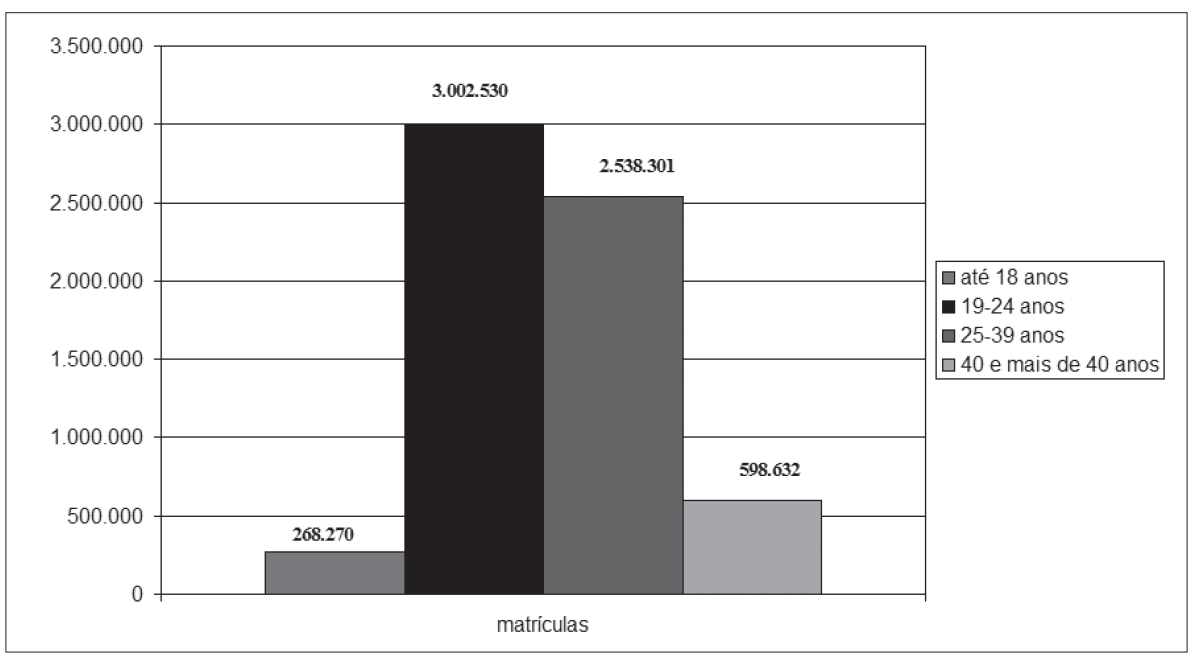

Fonte: INEP/MEC. Resumo Técnico Censo da Educação Superior de 2011 (2013).

Ou seja, a metade dos recursos para a educação superior é aplicada para estudantes que estão fora da idade escolar apropriada. Isto se deve, sem dúvida, ao fato de que o elitismo histórico do sistema educacional brasileiro excluiu, ao longo dos anos, muitas pessoas na idade apropriada - pessoas que agora, com as novas políticas públicas, vêem abrirem-se novas oportunidades de retomarem os seus estudos. Este é o aspecto positivo das medidas adotadas; o negativo é que fica evidente que as políticas de democratização do acesso estão beneficiando mais os mais velhos e menos os recém-saídos do ensino médio, até porque o ensino médio brasileiro não tem se expandido nos últimos anos. Ao contrário, o ensino médio está diminuindo. De 8.9 milhões de matrículas em 2005 passou para pouco mais de 8.3 milhões em 2012. E este é o paradoxo: as vagas da educação superior crescem, as matrículas da educação superior crescem e o ensino médio encolhe. Há algo decidida e profundamente errado 
na organização da educação brasileira — algo que as autoridades educacionais terão que enfrentar imediatamente. Trata-se de uma crise sistêmica que leva a uma profunda crise de responsabilidade.

$\mathrm{O}$ segundo chamamento à ação da CMES reza:

"Garantir igualdade de acesso a grupos insuficientemente representados".

Deve-se destacar que esta talvez tenha sido a área em que mais se avançou na educação superior brasileira nos últimos anos, com dois grandes programas nacionais, ambos bastante contestados em vários setores, mas ambos já consolidados. Refiro-me novamente ao Programa Universidade para Todos (ProUni) e ao Programa de Apoio a Planos de Reestruturação e Expansão das Universidades Federais (Reuni). O ProUni, que é um programa de bolsas e não de financiamento estudantil, já matriculou cerca de 1.000 .000 de jovens carentes na educação superior e o Reuni acelera um processo, sem precedentes na história do Brasil, de interiorização das universidades federais públicas e gratuitas. Ambos são, portanto, programas importantes para a inclusão dos insuficientemente representados - o Prouni por destinar-se exclusivamente a estudantes carentes e o Reuni por levar, pela primeira vez, as universidades federais para pequenas cidades do interior do Brasil. De todas as categorias administrativas das IES, as IFES são sabidamente as mais concentradas nas capitais dos estados. Eram, portanto, urgentes essas ações, que vieram a se caracterizar como a resposta brasileira à demanda da Unesco.

O grande desafio da exclusão, no entanto, passa hoje pelo aumento agressivo da taxa de escolarização líquida dos jovens de 15 a 17 anos, ou seja, do ensino médio, motivo pelo qual esta preocupação passou a fazer parte do novo PNE, aumentando a taxa de escolarização líquida deste nível de ensino para $85 \%$ até 2022. Sem este aumento, o ensino superior terá dificuldades de aumentar a sua taxa de escolarização (a proposta para o novo PNE apresentada pelo Ministério da Educação coloca a nova taxa para a educação superior em 33\%. Hoje ela está em torno de 17\%).

As previsões de ações afirmativas, embora sob fogo cruzado, fazem hoje parte da maioria das constituições nacionais da Região. Embora expressas de formas distintas, em geral o raciocínio que as sustenta é a percepção da necessidade do Estado de estabelecer tratamentos diferenciados e favoráveis aos grupos historicamente discriminados e excluídos para conseguir a igualdade real e efetiva entre os indivíduos.

Três questões despontam da análise do comportamento das IFES em relação à Lei das Cotas, Lei no. 12.711/2012 (BRASIL, 2012) após um ano de sua implantação: (1) a adequação de todas as IFES ao exigido pela Lei para 
2013; (2) a superação das metas para 2014 e 2015 por muitas instituições e (3) o atendimento pleno da cota de $50 \%$, prevista para 2016, por um número expressivo de universidades e Institutos federais.

A adequação de todas as IFES surpreende em parte em função do pouco tempo entre a sanção, a regulamentação da Lei e a operacionalização dos processos seletivos das universidades para 2013. Que Instituições sem qualquer política de ação afirmativa em vigor tenham conseguido fazer a tempo a negociação política interna e promover os devidos ajustes demonstra que a resistência às cotas no campus público é hoje menor do que se poderia a princípio supor.

Da mesma forma, a constatação de que muitas instituições já cumpriram as metas dos próximos anos e mesmo a meta para 2016 corrobora a percepção de que a comunidade acadêmica aceitou bem a política e está disposta a dar passos mais seguros e decisivos rumo à sua implementação.

Neste sentido cabem duas observações: (1) Os Institutos Federais (IFs) superam em muito as Universidades no ritmo de implementação da Lei e (2) as universidades novas superam em muito as mais antigas. Os dados mostram, por exemplo, que $83 \%$ dos institutos já cumprem a meta de 2016 contra apenas $34 \%$ das universidades. Entre as Universidades, universidades novas como a Universidade Federal da Fronteira Sul, a Universidade Federal do Recôncavo Bahiano, a Universidade Federal para a Integração Latino-Americana, a Universidade Federal do Pampa e várias outras já cumprem ou estão prestes a cumprir a meta de 2016, indicando que estas instituições, a exemplo dos Institutos Federais, já nasceram com mais cara de povo, ou seja, com uma identidade mais compatível com a da sociedade brasileira.

Entre os estados com os maiores percentuais de atendimento estão Rondônia, Paraná, Roraima, Santa Catarina e Mato Grosso, todos com mais de 50\% de atendimento. Entre os estados com os menores percentuais estão Rio de Janeiro, São Paulo, Rio Grande do Norte, Mato Grosso do Sul, Piauí e Paraíba, com percentuais que variam entre 28 e $32 \%$ de atendimento; portanto, também com níveis bem superiores aos 12,5\% exigidos para 2013 .

Se por um lado, temos muitos motivos para celebrar esta nova realidade nas instituições federais de educação superior, que representam cerca de $25 \%$ das matrículas da graduação, há que se atentar para o fato de que o ensino médio público brasileiro representa não $50 \%$, mas $87 \%$ das matrículas deste nível de ensino e que, no todo, o percentual de estudantes da graduação com origem na escola pública nem de longe se aproxima deste percentual. $\mathrm{O}$ fato de todas as IFES terem cumprido a meta prevista para 2013 não consegue esconder, por exemplo, que 17 das 59 universidades continuam com percentuais abaixo de 
$15 \%$ de vagas reservadas a estudantes do ensino médio público e que, portanto, há ainda um longo caminho a percorrer até que se possa reverter as atuais contradições entre o ensino médio e o superior.

Cabe, portanto, este alerta: Se por um lado a ágil implementação da lei significa a boa receptividade desta política de inclusão por parte da comunidade acadêmica das IFES, especialmente depois da decisão do Supremo Tribunal Federal, de abril de 2012, que julgou constitucional a política de cotas, minimizando, assim, o risco de ações na justiça contra as políticas de ações afirmativas até então adotadas, por outro lado, não se pode esquecer que os percentuais definidos em lei estão muito aquém dos percentuais representados pelas matrículas nas escolas públicas. Os estudantes da educação superior (pública e privada), que no primeiro ciclo do Enade diziam ter origem na escola pública de Ensino Médio, representavam 46\% do total. Este percentual subiu para 51\% em 2009, quando se completou o segundo ciclo do Enade. Ou seja, o crescimento do número estudantes oriundos do ensino médio público na educação superior já vem ocorrendo há alguns anos, em função das políticas públicas implementadas nos últimos anos (Prouni, Fies, Reuni) e deverá continuar a crescer, com o auxílio da Lei com certeza, mas também, simplesmente, por que continua muito aquém do que, dada a sua atual representação de $87 \%$, se poderia e se deveria esperar. Neste sentido, cabe observar que, a se considerar a média dos cursos de graduação como um todo, públicos e privados, as demandas da lei já estão em grande parte sendo cumpridas, mesmo por instituições não abrangidas pela Lei das Cotas.

O grande mérito da Lei, no entanto, não está tanto no aumento da média geral da presença de estudantes da escola pública no campus, mas no seu poder de induzir a melhoria da representação em todos os cursos de graduação, especialmente nos de alta demanda. Dados do Enade evidenciam de forma contundente a distância que existe entre (1) o que preconiza a Lei 12.711/2012 $(50 \%),(2)$ o que representa efetivamente a escola pública de ensino médio (87\%) e (3) o que ocorre em alguns cursos de graduação do País. Mais distantes dos $50 \%$ exigidos pela Lei estão os cursos de Medicina, com apenas $11 \%$ de seus estudantes oriundos dos $87 \%$ da escola pública, e de Odontologia, com $24 \%$. Direito se aproxima dos $50 \%$ exigidos pela Lei, mas percebe-se que ainda está muito distante da representação efetiva do Ensino Médio público. Mesmo cursos como História, Biblioteconomia, Pedagogia e as licenciaturas em geral, que já superam o exigido pela Lei, estão ainda a considerável distância da representação percentual do Ensino Médio público. Efetivamente, nenhum único curso de graduação atinge a paridade e somente 6 dos 47 cursos participantes 
dos dois primeiros ciclos do Enade têm mais de $70 \%$ de estudantes oriundos da escola pública. Esta realidade se estende às instituições públicas e privadas, estender a Lei das Cotas a todas elas, em especial às que recebem recursos e benefícios públicos via Fies, Prouni, bolsas de pós-graduação, etc., poderia trazer importantes benefícios ao país.

A medida se justifica principalmente pelas diferentes realidades encontradas nos diferentes cursos de graduação. Os dados mostram que os maiores percentuais de estudantes oriundos da escola pública estão em cursos de demanda mais baixa, enquanto, nos de demanda mais alta, os estudantes da escola pública (aí incluídos os pobres, pretos, pardos, indígenas) estão dramaticamente sub-representados.

As distorções existentes podem ser emblematicamente ilustradas pela análise das vagas hoje reservadas pelas IFES para pretos, pardos e indígenas (PPI), conforme estabelece a Lei. Das 162.176 vagas ofertadas pelas IFES, 30.290 $(19 \%)$ foram reservadas a este grupo social. Para os que pensam que isto é muito, é bom lembrar que este grupo representa $51 \%$ população brasileira, e que, portanto, em condições de igualdade de representação, a reserva deveria ser de 82.985 vagas. Por outro lado, os brancos, que representam $48 \%$ da população brasileira, nas IFES detêm $81 \%$ das vagas e, no campus brasileiro como um todo, $65 \%$ das matrículas.

Se é, portanto, inegável que a Lei das Cotas abriu importantes espaços para estudantes das escolas públicas e para os grupos sociais sub-representados e se já é perceptível a mudança de perfil no campus das Instituições privadas de Educação Superior, em função de políticas públicas implementadas nos últimos anos, há que se ter clareza de que muito ainda tem que ser feito para que esta mudança se estenda efetivamente a todos os cursos de graduação, públicos e privados, em especial aos de alta demanda. Só assim será possível ter nos próximos anos um campus mais justo e com mais cara de Brasil.

A partir do terceiro ciclo do Enade será possível confirmar ou não se a mudança de perfil sócio-econômico da graduação, observada nos últimos anos, veio para ficar. A se confirmar a atual tendência, ficará evidente que as políticas adotadas, embora lentas demais na sua execução aos olhos dos que delas precisam e dos indignados pela exclusão histórica, conquistaram o apoio social para torná-las irreversíveis. Estará, assim, pavimentado o caminho para um campus mais democrático e para uma educação superior brasileira mais capaz de criar oportunidades de mobilidade social para alunos trabalhadores, de baixa renda, pretos, pardos, indígenas e filhos de pai sem escolaridade, ampliando drasticamente as energias criativas da nação. 
De forma idêntica, a recente decisão da Corte Constitucional da Colômbia (Sentencia T-884/06), oficializando a política de cotas nas universidades, demonstra que avança a compreensão de que os direitos humanos dependem muitas vezes do tratamento desigual aos desiguais, removendo obstáculos normativos, econômicos e sociais que configurem desigualdades e que impedem que as pessoas desfrutem plenamente de seus direitos.

No segundo eixo do chamamento à ação, devemos destacar este:

"estabelecer e fortalecer os sistemas de garantia de qualidade e os marcos normativos apropriados".

Trata-se da garantia de qualidade a partir da avaliação baseada em critérios ou da afirmação de valores que nos referem ao que imaginamos que a educação superior deve ser. Note-se que o chamamento à ação fala em estabelecer e fortalecer os sistemas de garantia de qualidade, o que significa dizer que os participantes da CMES entendem que, em alguns casos, a região precisa ainda estabelecer mecanismos de avaliação que assegurem qualidade. Este não é exatamente o caso do Brasil, que tem, apesar de vários revezes, indecisões e indefinições, um sistema de avaliação, o Sinaes, implantado e em processo de consolidação e agora já em regime de revisão.

Como um todo, podemos dizer que a Ibero-América se organiza para que os sistemas de avaliação, acreditação e garantia de qualidade se instalem. Uma das mais importantes iniciativas neste cenário foi a criação, em maio de 2003, da Red Ibero-Americana de Agências de Acreditación de la Calidad de la Educación Superior (RIACES), que surge já como uma tentativa de organizar os esforços existentes nos diversos países da Região. E no âmbito desta rede operam agências importantes como:

Coneau - Comisión Nacional de Evaluación y Acreditación Universitaria Argentina

Aneca - Agencia Nacional de Evaluación de La Calidad y Acreditación - Espanha

CCA - Consejo Centroamericano de Acreditación - América Central

CSUCA - Consejo Superior Universitario Centroamericano

CNA - Consejo Nacional de Acreditación - Colômbia

CNAP - Comisión Nacional de Acreditación de Pregrado - Chile

Conea - Consejo Nacional de Evaluación e Acreditación de la Educación Superior -Equador 
JAN - Junta de Acreditación Nacional - Cuba

Inep - Instituto Nacional de Estudos e Pesquisas Educacionais Anísio Teixeira - Brasil

ANEAES - Agencia Nacional de Evaluación y Acreditación de la Educación Superior - Paraguai

SINAES - Sistema Nacional de Acreditación de la Educación Superior - Costa Rica

COPAES - Consejo para la Acreditación de la Educación Superior - México

CNU - Consejo Nacional de Universidades

ANR - Asamblea Nacional de Rectores - Peru

SEA - Sistema de Evaluación Académica - Venezuela

Observa-se, portanto, que a maioria dos países tem as suas agências nacionais de acreditação. Em alguns países, como Uruguai, República Dominicana, Panamá e Peru, a avaliação e a acreditação estão a cargo ou do Ministério da Educação ou de Universidades ou de Conselhos de Reitores. Este quadro se modifica à medida que novas agências vão sendo criadas. O Brasil neste momento, por exemplo, discute a criação de um novo Instituto (INSAES), especialmente voltado para a educação superior, juntando em uma mesma instituição as funções de avaliação, credenciamento de instituições, autorização e reconhecimentos de cursos, acreditação, supervisão e o poder de polícia do Estado brasileiro. Destaque-se que, diferentemente de outros países, o Brasil é, desde 1988, um Estado avaliador por excelência, sendo a avaliação no Brasil compulsória e tendo a ela fortemente atrelados os atos regulatórios do Ministério da Educação.

Cabe destacar ainda que ações importantes vêm sendo desenvolvidas no âmbito do Mercosul, onde existe hoje a RANA (Rede de Agências Nacionais de Acreditação), criada com o objetivo de buscar uma educação superior com qualidade e equidade, democratizando os sistemas educativos da região e estimulando a mobilidade e o intercâmbio acadêmico-científico e o Sistema Mexa e o seu sucedâneo Arcu-Sur de acreditação, que tem feito avaliações de algumas carreiras em diversos países da região. Estas iniciativas estão, portanto, em perfeita sintonia com o chamamento à ação da Conferência Mundial, todos na luta comum contra as fábricas de diplomas, nacionais e transfronteiriças, 
que se multiplicam. São esforços valiosos em um ambiente onde a cooperação regional em matéria de ensino superior ainda é tímida e perceptivelmente contaminada por preconceitos históricos e desconfianças mútuas (ver dificuldades no reconhecimento ou na validação de diplomas, e as dificuldades operacionais de uma universidade pública e gratuita como a recém-criada Universidade Federal para a Integração Latino-Americana (Unila).

Em resumo: há muito a ser conquistado nesta área e a participação do Brasil, na América Latina, até o momento, é tímida.

Por último, mas não menos importante, a questão da geração e do avanço do conhecimento, a inovação. A CMES orienta os países para que

[apoiem uma maior integração das TIC e [fomentem] a aprendizagem aberta e a distância, com vistas a atender o aumento da demanda de educação superior; [criem] mecanismos que permitam contrapor as repercussões negativas do êxodo de competências e, ao mesmo tempo, estimulem a mobilidade de docentes, estudantes e técnicos; [apoiem\} os países menos avançados e em desenvolvimento para que possam aproveitar as oportunidades que oferece a mundialização.

Com relação a isso gostaria de lembrar o que disse Biz Stone, um dos criadores do twitter durante a primeira reunião de cúpula sobre inovação na educação (WISE), em Doha, no Qatar: “O twitter é, por enquanto, uma rudimentar rede de conexão social". Estamos apenas no começo, garante, do pleno proveito a ser tirado dos bilhões de telefones celulares e contas de internet espalhados pelo mundo. Biz Stone, entre outras coisas, falava em Doha das possibilidades que se abriam para o que poderíamos denominar de sexta geração da educação a distância, a primeira tendo sido a da educação por correspondência, a segunda a educação pelo rádio, a terceira a educação pela televisão, a quarta a da telemática, integrando as telecomunicações com a informática, a quinta a do e-learning, ou do ensino virtual, e a sexta a integração efetiva das novas tecnologias de informação e comunicação à comunicabilidade móvel.

O criador do twitter esteve ao lado de Sugata Mitra, o autor do livro The Hole in the Wall (2005) - que, literalmente, abriu buracos em paredes junto às ruas de cidades para onde os bons professores não querem ir e instalou computadores. Mitra queria ver o que aconteceria com as crianças. Para a sua surpresa, as crianças aprenderam, em três meses, sozinhas, a usar o computador e, rapidamente, como todos nós, passaram a exigir um processador mais veloz. "Doutor", disseram-lhe no primeiro encontro alguns meses mais tarde: "Não dá pra colocar um processador mais rápido?" Mitra concluiu que, sem qualquer 
tipo de ajuda, os meninos de rua aprenderam $30 \%$ dos conteúdos de genética disponibilizados e, com o auxílio de um tutor, obtiveram resultados superiores aos dos estudantes das melhores escolas da Índia.

Mitra argumenta que hoje importa menos o que você sabe ou quem você conhece, e mais se você está ou não linkado. Já não estamos mais na época em que o computador apenas fazia melhor o velho trabalho: agora a própria ideia do velho trabalho está sendo redefinida, e a escola precisa rapidamente compreender esta redefinição para não tornar-se chata e obsoleta.

Entramos decididamente numa era em que conhecimento brota de coconstruções, produzidas em múltiplos sítios eletrônicos, não mais exclusivamente por gênios iluminados, mas por cidadãos comuns envolvidos com os seus afazeres diários, por inteligências coletivas e democráticas. Aos poucos, o usuário do Google questiona, e não raro com razão, as recomendações do médico, a originalidade do artista, o conhecimento do professor. $\mathrm{O}$ acesso fácil à informação, trazido pelas novas tecnologias, gerou a era do espanto, do desconforto, da instabilidade dos doutores acomodados, dos mestres oniscientes e dos pseudoespecialistas.

Para que a inteligência coletiva e democrática possa brotar em todos os cantos do planeta, ganhar escala e ser colocada efetivamente a serviço da humanidade, as universidades e a escola precisam mudar, tornando a inclusão digital de todos, especialmente a dos mais pobres, esquecidos e vulneráveis, a sua palavra de ordem deste milênio. A mensagem da CMES é esta: a de que nenhum único talento permaneça oculto e, acima de tudo, que o sistema educacional precisa estar disposto a colocar as novas tecnologias a serviço do ensino, da pesquisa e da extensão, tornando-as mais ágeis, mais interessantes e mais comprometidas com a sustentabilidade da vida no planeta. Para isso, professores e alunos terão que, entre outros, aprender a conviver com ambientes de aprendizagem auto-organizados, a lidar com tecnologias que tolerem o erro e a desenvolver sistemas de autoavaliação que possibilitem múltiplas trajetórias pedagógicas. Em suma, a educação terá que ter compromisso fundamental com a inovação. $\mathrm{O}$ que Biz Stone e Mitra propõem é um futuro que não mais replicará o presente. Será um futuro que trará à tona milhões de talentos que até hoje permaneciam ocultos pelo seu alijamento social e que a partir de agora poderão ser colocados a serviço da vida. Será um mundo novo, muito diferente do que o que hoje conhecemos, com novas oportunidades para todos.

Estarão os sistemas educacionais em condições de preparar os jovens para as demandas de adaptabilidade que se apresentam? A educação aberta e a distância têm tido grande desenvolvimento nos países da Ibero-América, especialmente 
na Espanha e no Brasil (no Brasil já representa $15 \%$ do total das matrículas), mas em toda a América Latina as experiências se multiplicam com um caráter ao mesmo tempo democratizante e mercantilista, como costuma acontecer com a educação superior como um todo. No entanto, a julgar pela resistência que as novas tecnologias ainda encontram em nossas universidades de elite, no Brasil, especialmente entre professores de cursos que devem formar os formadores de nossos filhos, não seria surpreendente que continuássemos, ainda por algum tempo, a educar para o passado, imaginando equivocadamente que esta educação funcionará no futuro. Não funcionará! A menos que aceitemos, passivamente, que se frustrem as nossas esperanças de construir um país soberano - avançado nas artes e nas ciências - é urgente que os professores e alunos, de nossas escolas e campi, sejam, a exemplo de outros setores mais progressistas da sociedade, expostos a um agressivo choque de novas tecnologias, antes que caiam em completo descrédito pela sua notória incapacidade de educar para os novos tempos. E isto não depende só dos professores. Depende, principalmente, de políticas públicas comprometidas com as novas possibilidades de interconectividade, comprometidas com o futuro.

Se em 2009 os destaques da WISE foram o Twitter de Biz Stone e os computadores para meninos carentes de Sugata Mitra, em 2010 o vencedor disparado foi o Ipad, com suas incríveis potencialidades para o redesenho de bibliotecas e a reinvenção da pedagogia. Hoje já é possível imaginar um aluno receber, no dia do seu ingresso na universidade, toda a bibliografia exigida em seu curso, podendo levar na mochila uma biblioteca maior e melhor do que a da maioria de nossas faculdades.

O trabalho dos professores será, portanto, profundamente afetado por essa nova tecnologia e é impossível imaginar que alunos da geração pós-Ipad aceitem métodos, ritmos e salas de aula incompatíveis com a agilidade e a facilidade de acesso ao conhecimento que a comunicabilidade móvel proporciona.

Durante a conferência, entreguei o meu cartão ao indiano sentado ao meu lado. Ao final da palestra, ele me surpreendeu: "Acabo de ler um paper seu, de 2009”, disse. "Gostaria de continuar em contato." Trocamos um cordial aperto de mão e não pude deixar de olhar para o seu Ipad com uma ponta de inveja. Ao seu lado, o meu notebook parecia um dinossauro.

Os investimentos feitos em Educação pelo Qatar não param nas conferências mundiais que organiza. Quem visita Doha, deve visitar a Education City - um campus multi-institucional e internacional. Nele estão presentes oito universidades do mundo, convivendo em harmonia com os alunos dos Estudos Islâmicos, seus valores e tradições. 
O projeto deverá transformar Doha num grande centro de pesquisa, preparando o país para a economia pós-carbono, para quando as reservas de petróleo e gás se esvaírem. A Education City, acreditam, é um dos empreendimentos capazes de gerar as competências que levem esse sonho a se tornar realidade.

Se os investimentos educacionais se transformarão em resultados, só o tempo dirá. Os investimentos em Educação ainda são apostas, mas para os qataris, depois de conquistarem a sede da copa de 2022 sendo um país sem tradição em futebol, "impossível” parece ser palavra proibida. Por isso mesmo, convictos, continuam a investir pesado em Educação. Claro que estamos falando de um país com muito dinheiro no momento e, portanto, muito distante da realidade que vivemos na América Latina, mas eu ousaria dizer, mesmo assim, que talvez esteja aí pelo menos uma lição para o Brasil: a aplicação inteligente dos recursos do pré-sal representa uma oportunidade única de recuperar a dívida histórica de suas populações marginalizadas e excluídas e preparar o país para enfrentar os desafios de um mundo sem petróleo ${ }^{6}$.

Investimentos expressivos em educação, acompanhados de intensa atividade de intercâmbio acadêmico internacional, continuam a ser, portanto, a melhor maneira de garantir que a Região possa usufruir plenamente das novas tecnologias e participar da geração e do avanço do conhecimento, aproveitando as oportunidades que a mundialização oferece. É alentador perceber que esta preocupação está contemplada em duas das metas do novo PNE brasileiro, tratando especificamente da promoção de intercâmbio científico e tecnológico, nacional e internacional, entre as instituições de ensino, pesquisa e extensão e da consolidação e ampliação de programas e ações de incentivo à mobilidade estudantil e docente em cursos de graduação e pós-graduação, em âmbito nacional e internacional. Em um país que experimentou longo período de isolamento dentro da América Latina, iniciativas como estas são, sem dúvida, promissoras.

Para o êxito destas macro-orientações deve-se construir um conjunto de políticas nacionais como salvaguardas, entre elas:

a) Ter incentivos atrativos para a formação de mestres e doutores;

b) Ter carreiras docentes bem estruturadas e valorizadas;

$6 \quad$ As referências aqui feitas às duas Conferências da WISE, a Sugata Mitra e Biz Stone foram quase na íntegra extraídas do livro do autor Construindo Outra Educação (2011). 
c) Apoiar, com recursos, a pesquisa, desde a iniciação científica para a identificação de talentos até os estudos avançados e, por fim,

d) Evitar a evasão de cérebros (o brain drain).

A CMES chama especial atenção a estas salvaguardas, por identificar que o brain drain é uma calamidade na maioria dos países pobres do mundo e também na América Latina.

As observações e alguns estudos brasileiros, no entanto, parecem não confirmar que o Brasil sofra do mal do brain drain, pelo menos nem de longe na mesma proporção que os demais países da região. O Brasil envia anualmente grande número de doutorandos ao exterior e, segundo estudos recentes, perde percentualmente poucos, provavelmente em função de sua carreira docente relativamente bem-estruturada nas universidades públicas, o que assegura aos doutorandos empregos quando do seu retorno ao país.

Pesquisando esse fenômeno, há alguns anos, Schwartzman concluiu que o Brasil não era fortemente impactado pela fuga de cérebros, diferentemente de seu país vizinho, a Argentina, pois grande parte dos entrevistados alegou interesse em voltar, o que era motivado principalmente por dois fatores: a) a dificuldade de adaptação ao país objeto do aprimoramento educacional ou profissional e b) condições favoráveis no país de origem (maior possibilidade de liderança e de ser socialmente útil e a manutenção do vínculo empregatício quando do retorno ao país). Quando a pesquisa foi realizada, apenas 5\%, em média, dos brasileiros que iam estudar no exterior por lá ficavam e trabalhavam, pois a maioria mantinha seus vínculos empregatícios no Brasil e, após os estudos, regressavam. (SCHWARTZMAN, 1973; 1978).

Reinaldo Guimarães (2002, p. 746) num estudo feito mais de duas décadas depois (2002), é ainda mais enfático:

Parece ocioso debater, em abstrato, se a migração de pesquisadores brasileiros para o exterior é ou não, hoje em dia, significativa. Certamente, entre nós não se observa a sangria vivida por muitos países do Terceiro Mundo, como a vizinha Argentina ou como alguns países da África e do Extremo Oriente (Tailândia, por exemplo). E é certo também que, de acordo com nossos números, perdemos para o exterior apenas 5,3 em cada 100 novos pesquisadores doutores colocados no mercado entre 1993 e 1999.

Mesmo que o Brasil não demonstre perda significativa, a questão do brain drain não perde a sua relevância para a região como um todo, permanecendo, 
portanto, como um importante, atual e permanente alerta a recomendação da Conferência Mundial.

Cabem, por fim, dois comentários sobre as recomendações da Unesco:

(1) o trabalho da Unesco se reveste de grande importância como orientador de políticas nacionais e

(2) estas orientações não são as únicas e estão em permanente conflito com outras e poderosas forças do mercado e de outros organismos internacionais.

Feitas estas observações, convém lembrar as palavras do relatório final da Conferência Regional de Educação Superior (UNESCO, 2008, p. 236) de Cartagena, Colômbia:

Esta Conferência Regional assinala que, apesar dos avanços na direção de uma sociedade que busca mudanças e referentes democráticos e sustentáveis, ainda faltam grandes transformações nos eixos que dinamizarão o desenvolvimento da região, entre os quais, um dos mais importantes, é a Educação e, em particular, a Educação Superior.

\section{REFERÊNCIAS}

AMARAL, Nelson Cardoso. Financiamento da educação superior: estado x mercado. São Paulo: Cortez; UNIMEP, 2003.

. O novo PNE e o financiamento da educação no Brasil: os recursos como um percentual do PIB. [SRB], 2013.

BRASIL. Lei $\mathrm{n}^{0}$ 9.394, de 20 de dezembro de 1996. LDB - estabelece as diretrizes e bases da educação nacional.

. Lei $\mathbf{n}^{\circ} \mathbf{1 0 . 1 7 2}$, de 10 de janeiro de 2001. Institui o Plano Nacional de Educação.

. SINAES - Sistema Nacional de Avaliação da Educação Superior. Brasília: INEP, 2003. (ver também a última edição desta publicação, pois a cada edição novas portarias são incluídas). 
2007.

. Plano de Desenvolvimento da Educação (PDE). Brasília: MEC,

. Lei $\mathbf{n}^{\mathbf{0}}$ 12.711, de 29 de agosto de 2012. Lei de Cotas: dispõe sobre o ingresso nas universidades federais e nas instituições federais de ensino técnico de nível médio.

. Decreto $\mathbf{n}^{0} \mathbf{7 . 8 2 4}$, de 11 de outubro de 2012. Regulamenta a Lei $12.711 / 2012$

EUA.CIA. The World Factbook 2010. Disponível em: $<$ https://www. cia.gov/library/publications/the-world-factbook/region/region_soa.html $>$. Central Intelligence Agency. Acesso em: 5 jul. 2013.

GUIMARÃES, Reinaldo. A diáspora: um estudo exploratório sobre o deslocamento geográfico de pesquisadores brasileiros na década de 90 . Dados, Rio de Janeiro, v. 45, p. 705-749, 2002.

INEP/MEC. Resumo Técnico Censo da Educação Superior de 2011. Brasília: INEP, 2013.

RISTOFF, Dilvo I. Construindo outra educação. Florianópolis: Insular, 2011.

RISTOFF, Dilvo I; GIOLO, Jaime (Orgs.). Educação Superior Brasileira 1991-2004. Brasília: INEP, 2006.

SCHWARTZMAN, Simon. Projeto Retorno - Avaliação do Impacto do Treinamento no Exterior, de Pessoal qualificado - Relatório Final. São Paulo: Fundação Getúlio Vargas, 1973. Disponível em: <www.schwartzman. org.br/sitesimon>. Acesso em: 5 jul. 2013.

. "Brain Drain: Pesquisa Multinacional?" In: OLIVEIRA, Edson Nunes de (Org.). A aventura sociológica. Rio de Janeiro: Zahar, Editora, 1978. p 67-84.

TOFLER, Alvin. Future schock. New York: Random House, 1970.

TROW, Martin. Reflections on the transition from elite to mass to universal access: forms and phases of higher education in modern societies since WWII. This paper is posted at the eScholarship Repository, University of California, 2005. Disponível em: <http://repositories.cdlib.org/igs/ WP2005-4, 2005>. Acesso em: 5 jul. 2013. 
UNESCO. Declaração da Conferência Mundial de Educação Superior. Paris: Unesco, 2009.

. Declaração da Conferência Regional de Educação Superior na América Latina e no Caribe. Cartagena: IESALC, 2008.

. Banco de Dados do Institute for Statistics - Data Centre. 2010.

Disponível em: $<$ http://stats.uis.unesco.org/unesco/TableViewer/document. aspx>. Acesso em: 5 jul. 2013. 